\title{
Early selection for resistance to Heterobasidion parviporum in Norway spruce is not likely to adversely affect growth and wood quality traits in late-age performance
}

\author{
Zhi-Qiang Chen ${ }^{1} \cdot$ Karl Lundén $^{2}$ (D) $\cdot$ Bo Karlsson $^{3} \cdot$ Ingrid Vos $^{3} \cdot$ Åke Olson $^{2} \cdot$ Sven-Olof Lundqvist ${ }^{4,5} \cdot$ Jan Stenlid ${ }^{2}$. \\ Harry X. Wu ${ }^{1,6} \cdot{\text { María Rosario García Gil }{ }^{1} \cdot \text { Malin Elfstrand }}^{2}$
}

Received: 14 November 2017 / Revised: 4 May 2018 / Accepted: 7 May 2018 / Published online: 17 May 2018

(c) The Author(s) 2018

\begin{abstract}
Infections with Heterobasidion parviporum devalue the Norway spruce timber as the decayed wood does not meet the necessary quality requirements for sawing. To evaluate the incorporation of disease resistance in the Norway spruce breeding strategy, an inoculation experiment with $H$. parviporum on 2-year-old progenies of 466 open-pollinated families was conducted under greenhouse (nursery) conditions. Lesion length in the phloem (LL), fungal growth in sapwood (FG) and growth (D) were measured on an average of 10 seedlings for each family. The genetic variation and genetic correlations between both LL, FG and growth in the nursery trial and wood quality traits measured previously from 21-year old trees in two progeny trials, including solid-wood quality traits (wood density, and modulus of elasticity) and fiber properties traits (radial fiber width, tangential fiber width, fiber wall thickness, fiber coarseness, microfibril angle and fiber length). For both LL and FG, large coefficients of phenotypic variation (>26\%) and genetic variation ( $>46 \%$ ) were detected. Heritabilities of LL and FG were 0.33 and 0.42 , respectively. We found no significant correlations between wood quality traits and growth in the field progeny trials with neither LL nor FG in the nursery trial. Our data suggest that the genetic gains may reach 41 and 52\% from mass selection by LL and FG, respectively. Early selection for resistance to H. parviporum based on assessments of fungal spread in the sapwood in nursery material, FG, will not adversely affect growth and wood quality traits in late-age performance.
\end{abstract}

Keywords Pathogen resistance $\cdot$ Heterobasidion annosum $\cdot$ Forest tree breeding $\cdot$ Picea abies $\cdot$ Root rot $\cdot$ Heritability genetic correlation

Communicated by Christian Ammer.

Zhi-Qiang Chen and Karl Lundén contributed equally to the manuscript.

Electronic supplementary material The online version of this article (https://doi.org/10.1007/s10342-018-1120-5) contains supplementary material, which is available to authorized users.

Karl Lundén

karl.lunden@slu.se

1 Department of Forest Genetics and Plant Physiology, Umeå Plant Science Centre, Swedish University of Agricultural Sciences, 90183 Umeå, Sweden

2 Department of Forest Mycology and Plant Pathology, Uppsala Biocenter, Swedish University of Agricultural Sciences, 7026, 75007 Uppsala, Sweden

\section{Introduction}

Norway spruce [Picea abies (L.) Karst.] is one of the most economically important conifer species in Europe. It is widely used for solid-wood products and production of pulp and paper. The timber is mainly utilized for construction and must meet certain quality requirements in terms of stability, strength, and stiffness (Hannrup et al. 2004). Infections with

3 Skogforsk, Ekebo 2250, 26890 Svalöv, Sweden

4 IIC, Rosenlundsgatan 48B, 11863 Stockholm, Sweden

5 RISE Bioeconomy, Drottning Kristinas väg, 11486 Stockholm, Sweden

6 CSIRO Plant Industry, Black Mountain Laboratory, Canberra, ACT 2601, Australia 
Heterobasidion annosum [(Fr.) Bref.] sensu lato (Dalman et al. 2010; Niemelä and Korhonen 1998) reduce the growth of the trees and devalue the Norway spruce logs since the decayed wood does not meet the necessary quality requirements for sawn timber. Infection is also problematic for the pulp and paper industry as the wood is rotted (representing a biomass loss) and discolored. This has made H. annosum s.l. the most severe wood-rotting fungus in economic terms (Bendz-Hellgren and Stenlid 1997). H. annosum s.l. is a species complex, with three members native in Europe, of which H. parviporum (Niemelä and Korhonen) has Norway spruce as its main host (Dalman et al. 2010; Niemelä and Korhonen 1998). In the mid-1980s, the average incidence of H. annosum s.l. infections was estimated to be $15 \%$ in Swedish Norway spruce trees (Stenlid and Wästerlund 1986). The disease incidence was projected to increase by $23 \%$ per decade in managed forests (Thor et al. 2005). Such projections where the model is linked to the temperature are associated with the climate change scenario for northern Europe that prolongs the season of H. annosum s.l. spores spread, thus providing a case for implementation of $H$. annosum s.l. resistance in the breeding programmes. It is well established that Norway spruce susceptibility to $H$. parviporum has a genetic component (Arnerup et al. 2010; Skrøppa et al. 2015a, b; Steffenrem et al. 2016), but it has been debated whether the genetic component is significant enough for resistance breeding.

It has been suggested that there may be constraints to the genetic and economic gains of breeding efforts aiming to increase growth, as growth and wood quality traits may be adversely correlated in conifers (Baltunis et al. 2007; Chen et al. 2016; Hong et al. 2014; Lenz et al. 2011; Steffenrem et al. 2009; Wu et al. 2008). Loehle and Namkoong (1987) hypothesized that there will be a trade-off between resistance traits in trees and selection for large volumetric growth. The growth-differentiation balance hypothesis (GDBH; Herms and Mattson 1992; Koricheva et al. 1998) provides a theoretical frame work for examination of trade-offs between growth and resistance (Villari et al. 2014). GDBH considers factors that limit growth and differentiation (such as investments in defensive structures and compounds). The trade-off under GDBH, with the hierarchical process level in the plant's metabolic organization (Koricheva et al. 1998), occurs between growth and constitutive defence at the whole-plant level (Herms and Mattson 1992). If resistance to H. parviporum in Norway spruce indeed is restricted by allocational trade-offs, as predicted by the GDBH, with wood quality or growth traits we would expect to find specific correlations between these traits and Heterobasidion resistance traits. Dealing with unwanted correlations between traits in breeding is a significant challenge (Hallingbäck et al. 2014). Until now few studies have addressed potential interactions between Heterobasidion resistance and growth traits (stem diameter), Swedjemark and Karlsson (2004) found positive correlations between tree size and FG while others report no correlations (Steffenrem et al. 2016; Swedjemark et al. 1997).

To further explore the genetic relationships between Heterobasidion resistance traits and both growth and wood quality traits in Norway spruce, we focused on a material of half-sib progenies from unrelated families in the Swedish Norway spruce breeding programme which previously had been characterized for growth, several solid-wood quality and fiber properties traits (Chen et al. 2014, 2016). The aim of this study was to: (1) characterize the additive genetic variation in a Norway spruce breeding population for susceptibility to $H$. parviporum after artificial inoculation; (2) estimate the genetic correlations between susceptibility and growth, solid-wood quality, and fiber-dimension traits; and finally (3) to estimate and discuss the response from selection for implementation of resistance breeding.

\section{Materials and methods}

\section{Measurements of solid-wood quality traits and fiber properties traits in the field progeny materials}

Two open-pollinated field progeny trials, S21F9021146 (F1146) and S21F9021147 (F1147), were established in 1990 in southern Sweden (Chen et al. 2014). Increment cores were sampled at age 21 years from 12 trees for each of 524 families. The material was analyzed with a SilviScan instrument (Evans 1994, 2006) at Innventia, Stockholm, for radial variations from pith to bark of wood quality traits. The traits measured were wood density (WD), microfibril angle (MFA), modulus of elasticity (MOE), radial fiber width (RFW), tangential fiber width (TFW), fiber wall thickness (FWT), and fiber coarseness (FC; Chen et al. 2014). Fiber length (FL) was measured with a laboratory fiber analyzer, the Kajaani FiberLab at SLU, Umeå (Table 1; Chen et al. 2016).

\section{Phenotyping for $H$. parviporum resistance in the nursery progeny materials}

\section{Plant material}

Open-pollinated families from 500 mother trees (genotypes) in the Swedish Norway spruce breeding program with an origin from south to central Sweden were sown in 2015. Of these, 243 families were in common with the progenies in the two field trials, S21F9021146 (F1146) and S21F9021147 (F1147). After the first growth season, the seedlings of 446 families with 6-12 progenies were randomized into a complete block design with three replications, where each family 
Table 1 Summary of growth, disease resistance- and wood quality traits

\begin{tabular}{lllllrlll}
\hline & Acron. & Year & Unit & $N$ & Mean & Min & Max & $N$ families \\
\hline Nursery trial & & & & & & & & \\
Diameter at point of inoculation & $\mathrm{D}$ & 2 & $\mathrm{~mm}$ & 4628 & 4.02 & 1 & 9 & 446 \\
Lesion Length & $\mathrm{LL}$ & 2 & $\mathrm{~mm}$ & 4547 & 7.61 & 1 & 104 & 446 \\
Fungal growth & $\mathrm{FG}$ & 2 & $\mathrm{~mm}$ & 4554 & 32.54 & 0 & 85 & 446 \\
Vitality & Vitality & 2 & $\mathrm{classes}$ & 4376 & 1.89 & 1 & 3 & 446 \\
Field progeny trials & & & & & & & & \\
Diameter at breast height & $\mathrm{DBH}_{12}^{\mathrm{a}}$ & 12 & $\mathrm{~mm}$ & 5712 & 67.15 & 6 & 146 & 524 \\
Diameter at breast height & $\mathrm{DBH}$ & 21 & $\mathrm{~mm}$ & 5693 & 113.10 & 21 & 241 & 524 \\
Height & $\mathrm{Ht}$ & 7 & $\mathrm{~cm}$ & 5711 & 222.40 & 15 & 475 & 524 \\
Density & $\mathrm{Density}$ & 21 & $\mathrm{Kg} / \mathrm{m}^{3}$ & 5497 & 429.80 & 298.20 & 429.8 & 524 \\
Microfibril angle & $\mathrm{MFA}$ & 21 & & 5497 & 14.16 & 4.60 & 32.83 & 524 \\
Modulus of elasticity & $\mathrm{MOE}$ & 21 & $\mathrm{GPa}$ & 5497 & 12.28 & 5.08 & 2069 & 524 \\
Radial fiber width & $\mathrm{RFW}$ & 21 & $\mathrm{um}$ & 5497 & 29.43 & 22.67 & 35.42 & 524 \\
Tangential fiber width & $\mathrm{TFW}$ & 21 & $\mathrm{um}$ & 5497 & 27.45 & 22.48 & 35.31 & 524 \\
Fiber wall thickness & $\mathrm{FWT}$ & 21 & $\mathrm{um}$ & 5497 & 2.16 & 1.51 & 3.43 & 524 \\
Fiber coarseness & FC & 21 & $\mathrm{ug} / \mathrm{m}$ & 5497 & 330.60 & 229.00 & 506.4 & 524 \\
Fiber length & FL & 21 & $\mathrm{~mm}$ & 3008 & 2.45 & 1.59 & 3.42 & 524 \\
\hline
\end{tabular}

Disease resistance traits were quantified in a nursery trial, and growth and wood quality traits were measured in two field progeny trials

Presenting total number of observations $(N)$, grand mean (Mean), minimum (Min), maximum (Max), number of families included in the materials ( $N$ families). The data on wood and fiber traits are presented as averages for cross-sections

${ }^{a}$ Subscripts of diameter at breast height $(\mathrm{DBH})$ at $1.3 \mathrm{~m}$ and height $(\mathrm{Ht})$ represent the tree ages when they were measured

was planted in 4-tree row-plots in plastic trays consisting of 24 individual $0.124 \mathrm{~L}$ plastic pots. The seedlings were grown for another season in Skogforsk's experimental forest tree nursery at Ekebo $\left(55^{\circ} 56^{\prime} 53.1^{\prime \prime} \mathrm{N} 13^{\circ} 6^{\prime} 52.2^{\prime \prime} \mathrm{E}\right)$ following ordinary watering and fertilization routines. No fungicides were used during cultivation.

\section{Inoculation experiment}

To prepare the inoculum, the heterokaryotic $H$. parviporum Rb175 (Stenlid 1987) grown on Hagem medium (Stenlid 1985) was allowed to colonize $6 \mathrm{~mm}$ diameter wood dowels for 6 weeks prior to the inoculation experiment.

At the day of inoculation, the vitality of the seedlings was measured according to the following score: (1) fully vital; (2) some loss of vitality (Fig. S1a) and (3) pronounced loss of vitality (Fig. S1b). To allow the fungus to enter the plant, bark was removed with a $6 \mathrm{~mm}$ diameter cork borer at $10 \mathrm{~cm}$ from the base of the seedling. A wooden dowel colonized by $H$. parviporum was fixated at the wound with Parafilm ${ }^{\circledR}$. The plants were kept under ambient light and temperature in the forest tree nursery and 21 days post-inoculation the seedlings were harvested.

At harvest the diameter at the point of inoculation (D) was measured and the induced defence responses in the phloem were estimated by measuring the lesion length (LL) spread upwards and downwards from the edge of the inoculation point on the inside of the bark. Fungal growth (FG) was measured according to the established protocols (Arnerup et al. 2010; Stenlid and Swedjemark 1988). The inoculated stem was then cut up into $5 \mathrm{~mm}$ discs and placed on moist filter papers in Petri dishes. To avoid contamination, the stem was cut from the top towards the point of inoculation and then from the bottom and towards the point of inoculation. After approximately 1 weeks' incubation under humid conditions, the presence of $H$. parviporum on the discs was determined by observation under the stereo-microscope (Arnerup et al. 2010; Stenlid and Swedjemark 1988). Samples with no conidia detected on the inoculation plug and a total lesion length of $2 \mathrm{~mm}$ or shorter were removed from the analysis as the inoculation was deemed as non-successful (Lind et al. 2014).

\section{Statistical analyses}

Due to the deviation from normal distribution of the lesion length data, a natural logarithm was used to transform the data to an approximation of a normal distribution (Steffenrem et al. 2016). Variance and covariance components for genetic analyses were estimated using ASReml4.1 (Gilmour et al. 2015) and the following linear mixed model for nursery data analysis was fitted: 
$y_{i j k l m}=\mu+B_{j}+V_{i}+P_{k}+D_{j k l m}+F_{l(k)}+e_{j k l m}$

where $y_{i j k l m}$ is the observation on the $m$ th tree from the $l$ th family within the $k$ th provenance in the $j$ th block and belongs to the $i$ th vitality class $\left(V_{i}\right), \mu$ is the general mean, $B_{j}, V_{i}$, and $P_{k}$ are the fixed effects of the jth block, the $i$ th vitality and the $k$ th provenance, respectively. The variable $F_{l(k)}$ is the random effect of the $l$ th family within the $k$ th provenance, and $e_{j k l m}$ is the random residual effect. $D_{i j k l m}$ is a covariate for diameter at inoculation point. Significance of the fixed effects was tested by Wald $F$-test. Non-significant fixed effects were dropped from the model after preliminary analysis. Estimates of heritability were obtained for each trait using variance components from the univariate analysis. Standard errors were estimated using the Taylor series expansion method (Gilmour et al. 2015).

As there is a good genetic connection between nursery trial and the two field progeny trials (243 common parents), the following linear mixed model for joint nursery and progeny data was fitted:

$y_{\text {hijklmn }}=\mu+S_{i}+B_{j(i)}+V_{h}+P_{l(k)}+D_{h i j k l m n}+F_{m(l(K))}+e_{h i j k l m n}$ where $y_{i j k l m n}$ is the observation on the $n$th tree from the $m$ th family within the $l$ th provenance in the $j$ th block within the $i$ th trial belongs to $h$ th vitality $\left(V_{h}\right), \mu$ is the general mean, $S_{i}, B_{j(i)}, V_{h}$, and $P_{l(k)}$, are the fixed effects of the $i$ th trial, the $j$ th block within the $i$ th trial, the $h$ th vitality and the $l$ th provenance within the $k$ th materials (including two types of data, from nursery and progeny), respectively. $D_{\text {hijklm }}$ is the covariate for diameter at inoculation point. The variable $F_{m(l(k))}$ is the random effect of the $m$ th family within the $l$ th provenance within the $k$ th materials and $e_{h i j k l m n}$ is the random residual effect. The random $F_{m(l(k))}$ is assumed to be normally distributed with the expectation value at zero and structured as: $\operatorname{var}\left(F_{m(l(k))}\right)=\left[\begin{array}{cc}\sigma_{a P}^{2} & \sigma_{a P N} \\ \sigma_{a P N} & \sigma_{a N}^{2}\end{array}\right] \otimes I$, where $\sigma_{a P}^{2}, \sigma_{a N}^{2}, \sigma_{a P N}$ are the additive variance for progeny data, additive variance for nursery data, and covariance for progeny and nursery data, respectively. The random $e_{h i j k l m}$ is assumed to be normally distributed with the expectation value at zero and structured as: $\operatorname{var}(e)=I \otimes\left[\begin{array}{lll}\sigma_{e P 1}^{2} & 0 & 0 \\ 0 & \sigma_{e P 2}^{2} & 0 \\ 0 & 0 & \sigma_{e N}^{2}\end{array}\right]$, where $\sigma_{e P 1}^{2}$, $\sigma_{e P 2}^{2}$ and $\sigma_{e N}^{2}$ are the residual variances for progeny trials F1146, F1147, and nursery data, respectively. Preliminary analyses indicated that there was no significant provenance by site effect for all traits and also no any provenance effect for lesion length and sapwood fungal growth. Therefore, these effects were removed in the final model. A two-tailed likelihood ratio test (LRT) against the null hypothesis of genetic correlation of zero was used to check the significance of genetic correlations between disease traits in the nursery and wood quality traits in the progeny trials.
The individual-tree narrow-sense heritability for each trait was estimated by

$\widehat{h}_{\mathrm{i}}^{2}=\frac{\hat{\sigma}_{\mathrm{a}}^{2}}{\hat{\sigma}_{p}^{2}}=\frac{4 \times \hat{\sigma}_{\mathrm{f}}^{2}}{\hat{\sigma}_{\mathrm{f}}^{2}+\hat{\sigma}_{\mathrm{e}}^{2}}$

assuming half-sib relationship and where $h_{\mathrm{i}}^{2}, \widehat{\sigma}_{a}^{2}, \widehat{\sigma}_{f}^{2}, \hat{\sigma}_{e}^{2}$, and $\widehat{\sigma}_{p}^{2}$ were narrow-sense heritability and additive genetic, family within provenance, residual, and phenotypic variance components, respectively. Phenotypic and genetic correlations between traits were calculated as:

$r=\frac{\widehat{\operatorname{Cov}}(x, y)}{\sqrt{\hat{\sigma}_{(x)}^{2} \times \hat{\sigma}_{(y)}^{2}}}$

where $\hat{\sigma}_{(x)}^{2}$ and $\hat{\sigma}_{(y)}^{2}$ are the estimated phenotypic or genetic variances for traits $x$ and $y$ or the same trait variances at two different ages, respectively, and $\widehat{\operatorname{Cov}}_{(x, y)}$ is the estimated phenotypic or genetic covariance between traits $x$ and $y$.

Coefficients of additive variation $\left(\mathrm{CV}_{\mathrm{a}}\right)$ and phenotypic variation $\left(\mathrm{CV}_{\mathrm{p}}\right)$ were calculated by dividing square root of additive and phenotypic variances by mean value of that trait, respectively.

Genetic gain $(G)$ was calculated using a selection intensity of $1 \%(i=2.67)$ :

$G=i \times \mathrm{CV}_{\mathrm{p}} \times h_{i}^{2}$

where $\mathrm{CV}_{\mathrm{p}}$ is coefficient of variation of phenotypic effect (calculated as the phenotypic standard deviation divided by the mean of a specific trait) and $h_{\mathrm{i}}^{2}$ is individual narrow-sense heritability.

To study the impact of early selection of disease resistance at late-age performance of tree growth and wood quality traits, the correlated response (CR) expressed as the percentage of the mean for those traits $(y)$ in field progeny trials to early selection based on nursery resistance traits $(x)$ is calculated as:

$\mathrm{CR}_{y}=\frac{i h_{x} h_{y} r_{a} \sigma_{p_{y}}}{M_{y}} \times 100$

where $h_{x}$ and $h_{y}$ are the square roots of individual narrowsense heritability for early selection trait $\mathrm{x}$ and correlated late-age trait $y, r_{\mathrm{a}}$ is the genetic correlation between traits $x$ and $y$, and $\sigma_{p_{y}}$ is the phenotypic standard deviation for trait $y, M_{y}$ is the mean value of trait $y$ (Falconer and Mackay 1996). 


\section{Results}

\section{Selection for the most disease resistant seedlings could lead to significant genetic gains}

The seedlings at the nursery had an average diameter of $4.02 \mathrm{~mm}$ at the point of inoculation (D) at the harvest. The mean LL 3 weeks after inoculation with $H$. parviporum was $7.61 \mathrm{~mm}$ long with a minimum of one $\mathrm{mm}$ to the maximum of $104 \mathrm{~mm}$. FG was on average $32.54 \mathrm{~mm}$ with variation from 0 to $85 \mathrm{~mm}$ (Table 1). Summary statistics of 11 growth and wood quality traits from two field progeny trials that have $46 \%$ common families with the nursery trial is shown in Table 1. In the two field progeny trials, each was scored in 524 families; diameter at breast height (DBH) increased from $67.15 \mathrm{~mm}$ at tree age $12-113.10 \mathrm{~mm}$ at tree age 21 . Height mean was $222.4 \mathrm{~cm}$ at age seven. The means for density, MFA, MOE, RFW, TFW, FWT, FC, and FL at trees age 21 were $429 \mathrm{~kg} / \mathrm{m}^{3}, 14.16^{\circ}, 12.28 \mathrm{Gpa}, 29.43,27.45,2.16$ um, $333.60 \mathrm{ug} / \mathrm{m}$, and $2.45 \mathrm{~mm}$, respectively. These mean values are based on cross-sectional averages, calculated by weighting data using areas of growth rings

Variance components, heritabilities, and coefficients of variation $(\mathrm{CV})$ are presented in Table 2 for the nursery trial. Heritabilities of $\mathrm{D}$ and disease resistance traits were all significant and varied from 0.26 for $\mathrm{D}$ to 0.42 for FG. $\mathrm{CV}_{\mathrm{a}}$ varied from $16.4 \%$ for $\mathrm{D}$ to $30.3 \%$ for $\mathrm{FG}$, and $\mathrm{CV}_{\mathrm{p}}$ were all more than $32.3 \%$, with the highest value of $47.0 \%$ for LL. It was estimated that genetic gains could be $22.4 \%, 41.4 \%$, $52.5 \%$ for D, LL, and FG, respectively, if the best $1 \%$ seedlings were selected.

\section{Fungal growth in sapwood correlates with lesion length and tree growth in the nursery trial but not in the two field progeny trials}

As expected, there were moderate phenotypic (0.48) and genetic (0.47) correlations between LL and FG in the nursery trial (Table 3$)$. LL had no correlation with D (0.03). However, FG had moderate positive genetic correlation with D (0.48). However, when disease-resistant traits data from the nursery experiment were matched with data on growth and wood quality traits for the same families
Table 3 Genetic (above diagonal) and phenotypic (below diagonal) correlations between traits in nursery trial

\begin{tabular}{llll}
\hline & LL & FG & $D$ \\
\hline LL & & $0.47(0.07)$ & $0.03(0.08)$ \\
FG & $0.48(0.01)$ & & $0.48(0.06)$ \\
$D$ & $0.05(0.02)$ & $0.27(0.02)$ & \\
\hline
\end{tabular}

Standard errors are shown in the parenthesis

$L L$ lesion length, $F G$ fungal growth, $D$ diameter at point of inoculation

scored from the two field progeny tests at age 21 , only weak and non-significant genetic correlations were found (Table 4). The genetic correlation between LL and growth and wood quality traits ranged from -0.22 to 0.11 . Similarly, the genetic correlations between FG and both growth and wood quality traits ranged from -0.23 to 0.16 . LL had the highest negative, but non-significant genetic correlation with MFA $(-0.22)$, while the FG had the highest negative and non-significant genetic correlation with FL $(-0.23)$. LL and FG also showed negligible genetic correlations with $\mathrm{Ht}_{7}, \mathrm{DBH}_{12}$, and $\mathrm{DBH}_{21}$ in the field trial $(-0.02-0.15)$.

\section{Expected responses for late-age growth and wood quality traits from early selection for disease resistances}

Early selection for resistance to Heterobasidion (lower values of LL and FG) had negligible effect on growth with the expected response for all growth traits less than $-1.17 \%$ with selection intensity of $1 \%$ (Table 5). For solid-wood quality traits, early selection for resistance to Heterobasidion had no negative effect, but had small negative impact on MFA and MOE if selection based on LL (5.08\% for MFA and $-4.17 \%$ for MOE). For fiber properties traits, early selection for resistance to Heterobasidion had negligible effect on traits RFW, TFW, and FC, but small negative effect on FWT $(-6.89 \%)$ if selection is based on LL and positive effect on FL (5.78 and $29.98 \%$ based on LL and FG, respectively).

Table 2 Variance components, heritabilities, coefficients of genetic $\left(\mathrm{CV}_{\mathrm{a}}\right)$ and phenotypic variations $\left(\mathrm{CV}_{\mathrm{p}}\right)$, and genetic gains $(G)$ for diameter at point of inoculation $(D)$, lesion length (LL), and fungal growth $(\mathrm{FG})$ in the nursery trial

\begin{tabular}{lrrrrrrr}
\hline Trait & \multicolumn{1}{c}{$\sigma_{a}^{2}$} & \multicolumn{1}{c}{$\sigma_{e}^{2}$} & \multicolumn{1}{c}{$\sigma_{p}^{2}$} & $h_{i}^{2}$ & $\mathrm{CV}_{\mathrm{a}}(\%)$ & $\mathrm{CV}_{\mathrm{p}}(\%)$ & $G(\%)$ \\
\hline $\mathrm{D}$ & 0.44 & 0.48 & 1.70 & $0.26(0.02)$ & 16.40 & 32.29 & 22.42 \\
LL & 0.20 & 0.56 & 0.61 & $0.33(0.04)$ & 26.97 & 46.96 \\
FG & 96.99 & 207.71 & 231.95 & $0.42(0.05)$ & 30.26 & 46.80 & 52.49 \\
\hline
\end{tabular}




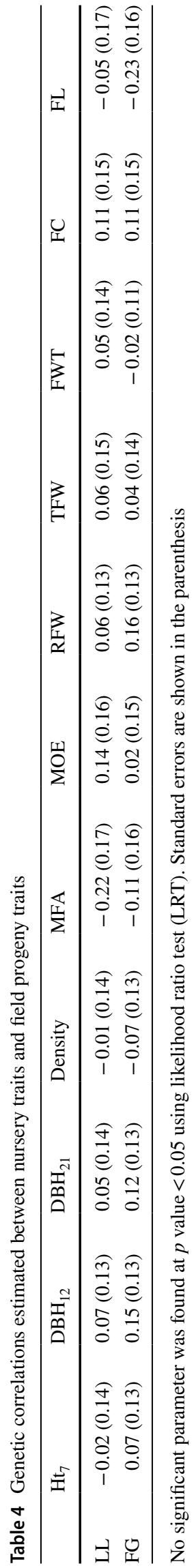

\section{Discussion}

The results presented in this work were based on an extensive resistance phenotyping work: on average ten twoyear-old progenies from each of 446 open-pollinated families were phenotyped for the resistance to $H$. parviporum by artificial inoculation. The scale of this study allowed us to use a larger phenotyped data set compared to most previous studies to estimate additive genetic variation for the resistance to H. parviporum in Norway spruce. This study found the largest narrow-sense heritability (LL with 0.33 and FG with 0.42 ) hitherto reported. In fact, with the low standard errors estimated in this study, the estimated narrow-sense heritability are comparable with previously reported broad-sense heritabilities of LL $(\leq 0.35)$ and FG $(\leq 0.27)$ for Heterobasidion spp. resistance (Skrøppa et al. 2015a; Swedjemark et al. 1997). Steffenrem et al. (2016) used parent-offspring regression to estimate the narrowsense heritability and obtained a relatively weak value of 0.16 for LL. In their two progeny trials, the narrow-sense heritabilities for LL varied from 0.14 to 0.26 for two single-site analyses and a joint-site analysis, and with high standard errors. Skrøppa et al. (2015a) showed a weak value of 0.21 for LL for the broad-sense heritability in Norway spruce (Skrøppa et al. 2015a). The narrow-sense heritabilities of LL and FG obtained in this study were higher than that of growth traits in the two field longterm progeny trials (Chen et al. 2015), but similar to most wood quality traits (0.33-0.50; Chen 2016). The size of genetic variation in a population is an important factor for breeding selection. We found strong coefficients of additive genetic $\left(\mathrm{CV}_{\mathrm{a}}>26 \%\right)$ and phenotypic $\left(\mathrm{CV}_{\mathrm{p}}>46 \%\right)$ variation for $H$. parviporum resistance traits. Steffenrem et al. (2016) used the LL as a measure of resistance to $H$. parviporum. The additive and phenotypic genetic variation for active defense in the phloem thus allows for a direct comparison between studies. $\mathrm{CV}_{\mathrm{a}}$ and $\mathrm{CV}_{\mathrm{p}}$ for $\mathrm{H}$. parviporum resistance is higher in the present study. Furthermore, both studies find higher genetic and phenotypic variation than those that were previously reported for growth traits and wood properties by Chen et al. (2016). It is possible that the additive genetic variation for resistance to $H$. parviporum in Norway spruce has been underestimated in previous studies and it may well be in the range where meaningful improvements can be made by breeding selection within a large breeding population. In fact our estimations suggest that the genetic gain could be up to $52.49 \%$ for control of fungal spread in the sapwood, if the best $1 \%$ seedlings in terms of that trait were selected.

The trade-off between growth, resistance, and fiber properties could be viewed as a result of whole-plant level allocation of energy at higher hierarchical process level 
Table 5 Expected response (\%) for growth and wood quality traits in field progeny trial when early selection for disease resistance (lower score of LL and FG) at nursery is conducted with selection intensity of $1 \%(i=2.67)$

\begin{tabular}{lrllllllllrr}
\hline & $\mathrm{Ht}_{7}$ & $\mathrm{DBH}_{12}$ & $\mathrm{DBH}_{21}$ & Density & MFA & MOE & RFW & TFW & FWT & FC & FL \\
\hline LL & 0.04 & -0.48 & -0.18 & 0.01 & 5.08 & -4.17 & -0.53 & -0.43 & -6.89 & -0.09 & 5.78 \\
FG & -0.15 & -1.17 & -0.48 & 0.06 & 2.86 & -0.67 & -1.58 & -0.33 & 3.11 & -0.10 & 29.98 \\
\hline
\end{tabular}

in the plant's metabolic organization (Herms and Mattson 1992; Koricheva et al. 1998). The only study, until now, examining genetic correlations between wood quality traits and resistance in Norway spruce indicates a moderate negative genetic correlation of resistance (LL) to $H$. parviporum with spiral grain (Steffenrem et al. 2016) suggesting a potential trade-off. Given that more than half of the mothers in the nursery trial also were part of previous progeny trials focused on growth, solid-wood quality and fiber property traits (Chen et al. 2014, 2016), we were able to use this overlap to analyze the correlations between those traits and $H$. parviporum resistance. We found no significant correlations between any wood quality traits and either LL or FG. There were no significant phenotypic and genotypic correlations between LL and growth traits in either the nursery phenotyping experiment (D) or the field progeny trials. These results seem to be in line with previous studies. Swedjemark and Karlsson (2004) reported a significant phenotypic correlation between growth and LL but no significant genetic correlation and several other studies report no significant correlations between growth and LL (Swedjemark et al. 1997, 2001). Generally, there appear to be no interaction between FG and growth, except in one study (Swedjemark and Karlsson 2004). The non-significant genetic correlation between the disease resistance, growth, and wood quality traits is favorable in designing multiple-traits breeding strategy for improvement of Norway spruce. In this study, we found that selections of FG or LL alone will cause a negligible effect on growth, density, and most of fiber properties traits. For MFA, MOE and FWT, the responses were small, but for FL a large positive effect was seen. Current breeding target in Norway spruce is mainly for growth and adaptation, with progressive incorporation of solidwood quality traits (Rosvall et al. 2011). If we select for resistance to Heterobasidion at nursery based on FG, the selected stocks will not adversely affect growth and wood quality traits. Therefore, incorporation of disease resistance to existing breeding strategy of Norway spruce targeted for the tree growth and solid-wood quality can be achieved relatively easily through independent culling or an index selection approach.

In line with these results, a weak and significant phenotypic correlation (0.27) and a significant moderate genetic correlation (0.47) were found between FG and larger stem diameter (D) in the nursery experiment. Thus, we see signs of a trade-off between growth and defense in young seedlings, as the bigger the FG or LL values are the more susceptible the seedling is. Genetic constraints between early plant growth potential, about the same growth phase as our nursery grown plants, and constitutive defensive investment have been found in Maritime pine ( $P$. pinaster), but only under nutrient-limited conditions (Moreira et al. 2015). If there are allocational trade-offs operating between growth, wood and fiber property traits and resistance to necrotrophic pathogens on a more general scale, then our set up based on material of different age and under different environmental conditions may not be appropriate to detect them as the genetic trade-offs between growth and defense may be strongly modulated by environmental conditions (Moreira et al. 2015). Nevertheless, these results further strengthen the arguments for including disease resistance in the Swedish Norway spruce breeding strategy.

A moderate additive genetic correlation between FG and LL for $H$. parviporum was found in this study, compared with a significantly higher genotypic correlation $(r=0.72)$ for H. annosum s.l. in a clonal trial (Swedjemark et al. 1997). This, and previously reported positive phenotypic correlations between FG and LL (Swedjemark and Karlsson 2004; Swedjemark and Stenlid 1997; Swedjemark et al. 1997, 2001), suggests that the measured traits together are relevant for estimating the relative susceptibility of Norway spruce to H.annosum s.l. or H. parviporum (Arnerup et al. 2010). Resistance to $H$. parviporum is a quantitative trait under polygenic control and the two traits FG and LL for Norway spruce are controlled by different areas of the genome (Lind et al. 2014). Lind et al. (2014) report two and four non-overlapping QTL regions, respectively, for LL and FG in a classical QTL study of one full-sib family of Norway spruce. One marker for one of the QTLs from that study has been validated and is available for deployment in breeding and selection (Nemesio-Gorriz et al. 2016).

Acknowledgements Financial support was received from the Swedish Foundation for Strategic Research (SSF), grant number RBP140040.We also acknowledge the Swedish research Council (VR) and the Swedish Governmental Agency for Innovation Systems (VINNOVA) and The Swedish Research Council for Environment, Agricultural Sciences and Spatial Planning (FORMAS). The SilviScan measurements were performed at Innventia, now part of RISE Bioeconomy, within the strategic research program Bio4Energy, funded by the Swedish 
government, where the samples were prepared and analyzed by Åke Hansson, Thomas Trost, Lars Olsson, and other researchers, and Thomas Grahn organized the data in the Bio4Energy Trait Database for the later steps of the evaluation. The funders had no role in study design, data collection and analysis, decision to publish, or preparation of the manuscript.

Open Access This article is distributed under the terms of the Creative Commons Attribution 4.0 International License (http://creativeco mmons.org/licenses/by/4.0/), which permits unrestricted use, distribution, and reproduction in any medium, provided you give appropriate credit to the original author(s) and the source, provide a link to the Creative Commons license, and indicate if changes were made.

\section{References}

Arnerup J, Swedjemark G, Elfstrand M, Karlsson B, Stenlid J (2010) Variation in growth of Heterobasidion parviporum in a full-sib family of Picea abies. Scand J For Res 25:106-110. https://doi. org/10.1080/02827581003730799

Baltunis BS, Wu HX, Powell MB (2007) Inheritance of density, microfibril angle, and modulus of elasticity in juvenile wood of Pinus radiata at two locations in Australia. Can J For Res 37:2164 2174. https://doi.org/10.1139/x07-061

Bendz-Hellgren M, Stenlid J (1997) Decreased volume growth of Picea abies in response to Heterobasidion annosum infection. Can J For Res 27:1519-1524

Chen Z-Q (2016) Quantitative genetics of Norway spruce in Sweden. Doctoral thesis, Swedish University of Agricultural Sciences

Chen Z-Q, García Gil MR, Karlsson B, Lundqvist S-O, Olsson L, Wu HX (2014) Inheritance of growth and solid wood quality traits in a large Norway spruce population tested at two locations in southern Sweden. Tree Genet Genomes 10:1291-1303. https:// doi.org/10.1007/s11295-014-0761-x

Chen Z-Q, Karlsson B, Lundqvist S-O, García Gil MR, Olsson L, Wu HX (2015) Estimating solid wood properties using Pilodyn and acoustic velocity on standing trees of Norway spruce. Ann For Sci. https://doi.org/10.1007/s13595-015-0458-9

Chen Z-Q, Karlsson B, Mörling T, Olsson L, Mellerowicz EJ, Wu HX, Lundqvist S-O, García Gil MR (2016) Genetic analysis of fiber dimensions and their correlation with stem diameter and solidwood properties in Norway spruce. Tree Genet Genomes 12:123. https://doi.org/10.1007/s11295-016-1065-0

Dalman K, Olson A, Stenlid J (2010) Evolutionary history of the conifer root rot fungus Heterobasidion annosum sensu lato. Mol Ecol 19:4979-4993

Evans R (1994) Rapid measurement of the transverse dimensions of tracheids in radial wood sections from Pinus radiata. Holzforschung 48:168-172. https://doi.org/10.1515/hfsg.1994.48.2.168

Evans R (2006) Wood stiffness by X-ray diffractometry. In: Stokke DD, Groom HL (eds) Characterization of the cellulosic cell wall. Wiley, Hoboken, pp 138-146

Falconer D, Mackay T (1996) Introduction to quantitative genetics, 4th edn. Longman, New York

Gilmour AR, Gogel BJ, Cullis BR, Welham SJ, Thompson R (2015) ASReml user guide release 4.1. VSN International Ltd, Hemel Hempstead

Hallingbäck HR, Sánchez L, Wu HX (2014) Single versus subdivided population strategies in breeding against an adverse genetic correlation. Tree Genet Genomes 10:605-617

Hannrup B, Cahalan C, Chantre G, Grabner M, Karlsson B, Le Bayon I, Jones GL, Muller U, Pereira H, Rodrigues JC, Rosner S,
Rozenberg P, Wilhelmsson L, Wimmer R (2004) Genetic parameters of growth and wood quality traits in Picea abies. Scand J For Res 19:14-29. https://doi.org/10.1080/02827580310019536

Herms DA, Mattson WJ (1992) The dilemma of plants: to grow or defend. Q Rev Biol 67:283-335

Hong Z, Fries A, Wu HX (2014) High negative genetic correlations between growth traits and wood properties suggest incorporating multiple traits selection including economic weights for the future Scots pine breeding programs. Ann For Sci 71:463-472. https:// doi.org/10.1007/s13595-014-0359-3

Koricheva J, Larsson S, Haukioja E, Keinänen M (1998) Regulation of woody plant secondary metabolism by resource availability: hypothesis testing by means of meta-analysis. Oikos 83:212-226

Lenz P, MacKay J, Rainville A, Cloutier A, Beaulieu J (2011) The influence of cambial age on breeding for wood properties in Picea glauca. Tree Genet Genomes 7:641-653. https://doi.org/10.1007/ s11295-011-0364-8

Lind M, Källman T, Chen J, Ma X-F, Bousquet J, Morgante M, Zaina G, Karlsson B, Elfstrand M, Lascoux M (2014) A Picea abies linkage map based on SNP markers identifies QTLs for four aspects of resistance to Heterobasidion parviporum infection. PLoS ONE 9:e101049

Loehle C, Namkoong G (1987) Discussion paper: constraints on tree breeding: growth tradeoffs, growth strategies, and defensive investments. For Sci 33:1089-1097

Moreira X, Zas R, Solla A, Sampedro L (2015) Differentiation of persistent anatomical defensive structures is costly and determined by nutrient availability and genetic growth-defence constraints. Tree Physiol 35:112-123. https://doi.org/10.1093/treephys/tpu106

Nemesio-Gorriz M, Hammerbacher A, Ihrmark K, Källman T, Olson $\AA$, Lascoux M, Stenlid J, Gershenzon J, Elfstrand M (2016) Different alleles of a gene encoding leucoanthocyanidin reductase (PaLAR3) influence resistance against the fungus Heterobasidion parviporum in Picea abies. Plant Physiol 171:2671-2681

Niemelä T, Korhonen K (1998) Taxonomy of the genus Heterobasidion. In: Woodward S, Stenlid J, Karjalainen R, Hüttermann A (eds) Heterobasidion annosum: biology, ecology, impact and control. CAB International, Wallingford, pp 27-33

Rosvall O, Ståhl P, Almqvist C, Anderson B, Berlin M, Ericsson T, Eriksson M, Gregorsson B, Hajek J, Hallander J (2011) Review of the Swedish tree breeding programme. Arbetsrapport Skogforsk, Uppsala Science Park, Uppsala

Skrøppa T, Solheim H, Hietala A (2015a) Variation in phloem resistance of Norway spruce clones and families to Heterobasidion parviporum and Ceratocystis polonica and its relationship to phenology and growth traits. Scand J For Res 30:103-111. https://doi. org/10.1080/02827581.2014.963144

Skrøppa T, Solheim H, Steffenrem A (2015b) Genetic variation, inheritance patterns and parent-offspring relationships after artificial inoculations with Heterobasidion parviporum and Ceratosystis polonica in Norway spruce seed orchards and progeny tests. Silva Fenn 49:1-12

Steffenrem A, Kvaalen H, Hoibo OA, Edvardsen OM, Skroppa T (2009) Genetic variation of wood quality traits and relationships with growth in Picea abies. Scand J For Res 24:15-27. https:// doi.org/10.1080/02827580802641215

Steffenrem A, Solheim H, Skrøppa T (2016) Genetic parameters for wood quality traits and resistance to the pathogens Heterobasidion parviporum and Endoconidiophora polonica in a Norway spruce breeding population. Eur J For Res 135:815-825. https://doi. org/10.1007/s10342-016-0975-6

Stenlid J (1985) Population structure of Heterobasidion annosum as determined by somatic incompatibility, sexual incompatibility, and isoenzyme patterns. Can J Bot 63:2268-2273. https://doi. org/10.1139/b85-322 
Stenlid J (1987) Controlling and predicting the spread of Heterobasidion annosum from infected stumps and trees of Picea abies. Scand J For Res 2:187-198

Stenlid J, Swedjemark G (1988) Differential growth of S-and P-isolates of Heterobasidion annosum in Picea abies and Pinus sylvestris. Trans Br Mycol Soc 90:209-213

Stenlid J, Wästerlund I (1986) Estimating the frequency of stem rot in Picea abies using an increment borer. Scand J For Res 1:303-308

Swedjemark G, Karlsson B (2004) Genotypic variation in susceptibility following artificial Heterobasidion annosum inoculation of Picea abies clones in a 17-year-old field test. Scand J For Res 19:103-111. https://doi.org/10.1080/02827580310018032

Swedjemark G, Stenlid J (1997) Between-tree and between-isolate variation for growth of S-group Heterobasidion annosum in sapwood of Picea abies cuttings. Can J For Res 27:711-715. https://doi. org/10.1139/cjfr-27-5-711

Swedjemark G, Stenlid J, Karlsson B (1997) Genetic variation among clones of Picea abies in resistance to growth of Heterobasidion annosum. Silvae Genet 46:369-374
Swedjemark G, Stenlid J, Karlsson B (2001) Variation in growth of Heterobasidion annosum among clones of Picea abies incubated for different periods of time. For Pathol 31:163-175

Thor M, Ståhl G, Stenlid J (2005) Modelling root rot incidence in Sweden using tree, site and stand variables. Scand J For Res 20:165-176

Villari C, Faccoli M, Battisti A, Bonello P, Marini L (2014) Testing phenotypic trade-offs in the chemical defence strategy of Scots pine under growth-limiting field conditions. Tree Physiol 34:919-930

Wu HX, Ivković M, Gapare WJ, Matheson AC, Baltunis BS, Powell MB, McRae TA (2008) Breeding for wood quality and profit in radiata pine: a review of genetic parameters. N Z J For Sci 38:56-87 